\title{
A Análise da Motivação de Alunos a partir de um Processo de Escolha, Preparação e Apresentação de Experimentos de Química
}

\author{
An Analysis of Student Motivation in the Process of Choosing, Preparing \\ and Presenting Chemistry Experiments
}

\author{
Beatriz Derisso Faitanini, Paulo Sergio Bretones
}

Palavras-chave Resumo O objetivo desse trabalho foi o estudo do perfil motivacional

Motivação, de alunos compreendendo quais fatores os motivam para o estudo Ensino de química, da Química. Como referencial teórico, utilizou-se a Teoria da

Teoria da Autodeterminação, propondo um continuum de autodeterminação Autodeterminação. com seis níveis motivacionais. Os dados foram coletados entre alunos do $1^{\circ}$ ano do Ensino Médio, a partir de um processo de escolha, preparação e demonstração de experimentos de Química; por meio da aplicação de dois tipos de questionários, um aberto e outro utilizando a escala Likert. A análise dos dados mostrou que antes da realização do projeto os alunos apresentavam valores de Ranking Médio (RM) mais altos para a Regulação Integrada e mais baixos para as formas menos autodeterminadas de motivação. Após a realização do projeto os valores de RM para a Regulação Integrada e Motivação Intrínseca aumentaram ainda mais, enquanto os valores para as formas menos autodeterminadas tiveram um decréscimo. Isso pode ser uma evidência de variação no perfil motivacional dos alunos, com relação aos motivos para a aprendizagem. Os dados evidenciam que a ocorrência de situações que favorecem a satisfação das necessidades psicológicas básicas desperta o entusiasmo dos alunos em situações consideradas favoráveis à promoção da motivação intrínseca. Buscamos contribuir para um aprofundamento sobre a motivação para o estudo da química, relacionando à satisfação das necessidades psicológicas básicas durante esse processo com a promoção da motivação. 
Keywords Abstract This paper aims at studying the motivational profile Motivation; of students focusing on which factors bring them motivation for Chemistry teaching; studying Chemistry. The Self-Determination Theory was used as the Self-determination theoretical framework, outlining six levels of motivation, in a way Theory. to propose a self-determination continuum. The data was collected using two questionnaires, one of which was open-ended and the other was based on the Likert scale. They were applied to students in the first year of High School, through a process of choice, preparation and demonstration of experimental practices of Chemistry. The data analysis showed that, before the implementation of this project, students' Average Ranking values were higher in the Integrated Regulation than in the less self-determined motivational forms. After the project was carried out, the average ranking values for Integrated Regulation and Intrinsic Motivation increased even more, while those related to less self-determined forms decreased. This could be an evidence of variation in the students' motivational profiles related to the reasons for learning. The data provided elements that confirm that including situations that favor the satisfaction of basic psychological needs fosters students' enthusiasm in cases considered favorable to the promotion of intrinsic motivation. The objective was to contribute for understanding motivation in Chemistry studies, relating it to basic psychological needs during the process of promotion of motivation.

\section{Introdução}

Ao observar um aluno pouco interessado nas atividades escolares, podemos atribuir sua falta de motivação a fatores familiares, econômicos, emocionais, por outras atividades não relacionadas à escola, entre outros. Porém, a motivação de um aluno, bem como suas causas, não é um assunto que se restrinja somente a ele, a família ou a outras condições que não pertencem ao ambiente escolar - o que ocorre é a combinação desses fatores, com maior relevância no que acontece dentro da escola e da sala de aula (Boruchovitch \& Bzuneck, 2000).

Entre os problemas para a construção de conhecimentos químicos, o mais importante deles, segundo Pozo e Crespo (2009) se refere à natureza abstrata da Química, pois é esperado que os alunos compreendam e analisem as propriedades e transformações da matéria, mas para que isso ocorra eles precisam defrontar-se com um número grande de leis e conceitos fortemente abstratos e estabelecer conexões entre esses conceitos e os fenômenos estudados, só que eles se deparam com uma linguagem altamente simbólica e formalizada que dificulta todo esse processo. De acordo com Cardoso e Colinvaux (2000), "alguns alunos consideram a disciplina desinteressante ou sem utilidade em sua vida cotidiana, a forma como a matéria é apresentada e as dificuldades em sua assimilação desestimulam e contribuem para a falta de motivação" (p. 402). 
Uma das formas de mudar essa imagem da Química é a utilização de formas alternativas de ensino. Destacamos, dentre elas, a experimentação, que pode funcionar como estratégia eficiente na formulação de problemas reais que possibilitem a contextualização e o estímulo de questionamentos, podendo facilitar a motivação dos alunos e mostrando a importância de se desenvolver uma visão crítica do mundo; porém, essa metodologia não deve ser somente baseada nas aulas experimentais do tipo "receita de bolo", aonde os alunos recebem um roteiro que devem seguir para obter os resultados esperados (Guimarães, 2009). Cremos que o processo de escolha e preparação de experimentos, bem como a saída da sala de aula, podem contribuir para o aumento dessa motivação.

Fazendo um levantamento das pesquisas sobre motivação no ensino de Química, percebemos que ainda há poucos estudos sobre esse tema, dentre eles podemos destacar alguns trabalhos. Cardoso e Colinvaux (2000) buscaram identificar os fatores que motivam os alunos para o estudo da Química, apontando o papel das relações sociais e escolares como um desses fatores; as autoras preparam um questionário com 9 perguntas, a primeira questão era "Você gosta de estudar Química? Por que?", 72\% dos participantes afirmaram que gostam de estudar Química, porém alguns alunos consideram a disciplina desinteressante ou sem utilidade em sua vida cotidiana, atribuindo esse desinteresse principalmente a forma como a disciplina é apresentada e a dificuldade de assimilação, alegando que esses fatores desestimulam e contribuem para a falta de motivação (Cardoso \& Colinvaux, 2000). Pontes et al. (2008) buscaram diagnosticar os principais problemas do processo de ensino-aprendizagem e destacar aspectos sobre a motivação dos alunos para estudar Química a partir da contextualização dos conteúdos e do uso de atividades experimentais durante a prática pedagógica; a partir da análise dos dados os pesquisadores observaram que 58\% dos professores afirmam utilizar atividades experimentais em suas aulas, mas 55\% dos alunos afirmam que seus professores não realizam essas atividades em sala de aula, com base nesse resultado os autores deixam um questionamento para os leitores: "Será que o uso desse recurso está sendo identificado pelos alunos como uma prática experimental? Pois percebemos que não há um consenso entre o que alunos e professores relatam" (Pontes et al., 2008). Corrêa (2009) procurou analisar o perfil motivacional e os fatores que podem influenciar o aprendizado da Química a partir da orientação motivacional de alunos que participaram de um curso sobre metais; em relação aos resultados obtidos podemos destacar o tipo de atividade capaz de influenciar o aprendizado, segundo a autora as atividades de leitura e discussão dos textos, o uso de imagens e filmes e a realização de atividades práticas e dinâmicas foram consideradas interessantes pelos alunos (Corrêa, 2009). Marangoni et al. (2013) procurou traçar o perfil motivacional dos alunos do primeiro ano do Ensino Médio a partir da Teoria da Autodeterminação; a análise dos dados mostrou que esses alunos possuem um baixo grau de Desmotivação, apresentando a Regulação Introjetada como perfil motivacional e ressaltando a associação que os estudantes podem fazer entre receber uma recompensa e realizar uma atividade (Marangoni et al., 2013). Severo (2014) realizou uma pesquisa 
que teve como objetivo fazer o levantamento do perfil motivacional de alunos de três escolas públicas da cidade de São Carlos, a partir da Teoria da Autodeterminação; as três escolas apresentaram alunos com o mesmo perfil motivacional, a Regulação Integrada. Segundo o autor, é preciso continuar as melhoras do ensino, considerando aspectos importantes como recursos didáticos, laboratórios, a família, entre outros, considerando que atividades experimentais ou mesmo as aulas com outros recursos didáticos tendem a estimular mais a motivação e assim o rendimento dos estudantes (Severo, 2014).

Essas pesquisas mostram que os fatores que contribuem ou não para a motivação do aluno para o estudo e aprendizado da Química são variados. No entanto, mesmo diante da variedade de fatores, podemos considerar que o contexto escolar, as metodologias, os recursos didáticos, as relações escolares e, principalmente, as atividades experimentais, são fundamentais na adoção das orientações motivacionais dos alunos.

Como apresentado nas pesquisas, a forma como os conteúdos são abordados é determinante para motivar os alunos para o aprendizado. Superar o modelo de ensino do tipo transmissão pode contribuir para o aumento do interesse dos alunos para o aprendizado, pois considera-se que a aprendizagem não está ocorrendo por simples aquisição de um conteúdo que o estudante não conhecia, mas sim pelas interações ocorridas durante o processo de ensino-aprendizagem. À medida que o professor começa a valorizar e incentivar a participação do estudante em suas aulas, o envolvimento dos alunos nas atividades passa a ser maior, pois os alunos tendem a sentir-se aceitos como tal (Corrêa, 2009). De acordo com Cardoso e Colinvaux (2000), os estudantes reconhecem as atividades experimentais como momentos diferenciados e interessantes durante uma aula de química. Essas atividades possuem um papel fundamental no ensino de Química, pois são eficazes no processo de compreensão dos fenômenos e dos conceitos científicos relacionados. Para que essas atividades sejam eficazes é necessário que haja uma interação na qual o aluno deixe de ser um agente passivo e tenha a oportunidade de relacionar o que foi dito em sala de aula com o exposto nas atividades experimentais. É indiscutível a importância da experimentação no ensino de química, pois a aula prática é uma sugestão de estratégia de ensino que pode contribuir para a motivação na aprendizagem (Pontes et al., 2008).

Considerando o exposto acima e com o intuito de realizar uma pesquisa no âmbito do ensino de Química sobre a importância do processo de escolha, preparação e divulgação de experimentos na motivação dos alunos do Ensino Médio, tornou-se necessária a elaboração de uma questão: "Quais são as contribuições da participação no processo de escolha, preparação e divulgação de experimentos de Química na motivação dos alunos do Ensino Médio?" Levando em consideração aquilo que observamos dentro das escolas de educação básica, onde pouco ou nada é feito para motivar o interesse e a curiosidade dos alunos, acreditamos que tal trabalho pode contribuir de maneira eficaz para a contextualização dos conteúdos, desconstruindo conceitos enraizados por práticas pedagógicas não tão adequadas, aumentando a motivação necessária para o aprendizado. 
Para responder à questão, foi realizada uma pesquisa utilizando como referencial teórico a Teoria da Autodeterminação de Deci e Ryan (1985), buscando compreender como esse processo pode influenciar na motivação do aluno para o estudo da Química. Dessa maneira conseguimos compreender como um processo de escolha, preparação e apresentação de experimentos pode influenciar no perfil motivacional dos alunos, analisando principalmente a relação da satisfação das necessidades psicológicas básicas, com o deslocamento no continuum da motivação dos alunos pesquisados.

\section{Fundamentação teórica}

O conceito de motivação vem se modificando ao longo do tempo, sendo encarada no início apenas como uma "força interna", como podemos observar em Vernon (1969) “a motivação é encarada como uma espécie de força interna que emerge, regula e sustenta todas as nossas ações mais importantes" (p. 1, tradução nossa) ${ }^{1}$, e passando pelas concepções contemporâneas que tratam a motivação como um "processo psicológico", como visto em Pintrich e Schunk (2002) "a motivação é um processo e não um produto" (p. 4, tradução nossa) ${ }^{22}$, ou seja, a motivação, de maneira geral, é aquilo que move ou coloca em ação uma pessoa. As teorias mais antigas que tratam da aprendizagem apontavam a motivação apenas como uma pré-condição importante, atualmente as investigações nos permitem concluir que a relação entre motivação e aprendizagem vai muito além dessa pré-condição.

Uma visão importante nos é apresentada por Vygotsky (1991) quando menciona, de uma forma resumida, que o processo de ensino-aprendizagem pode ser definido como a maneira com que os sujeitos adquirem novos conhecimentos, modifica o comportamento e desenvolvem competências; essa mudança do comportamento é relativamente estável, mais ou menos constante, fruto da experiência, da observação e da prática motivada. Podemos destacar que a aprendizagem é influenciada pela motivação, inteligência e incentivo, um aluno motivado possui comportamento ativo no processo de aprendizagem, tornando esse processo mais eficiente.

As atuais teorias sobre motivação que têm como objeto de estudo o pensamento do indivíduo são chamadas de "concepções contemporâneas", das quais podemos destacar as Teorias Cognitivas e Sociocognitivas, que consideram a importância das influências sociais na ocorrência dos comportamentos, e por isso são adotadas como os principais referenciais para o estudo da aprendizagem escolar (Severo, 2014). Dentre as Teorias Sociocognitivas podemos destacar a Teoria da Autodeterminação [Self-Determination Theory - SDT] de Deci e Ryan, que leva em consideração o perfil motivacional de cada indivíduo e a influência do contexto externo no favorecimento das formas autodeterminadas de motivação.

1 [...motivation is thougth of as some kind of internal force which arouses, regulates and sustains all our more importante actions].

2 [Motivation is a process rather than a product]. 


\section{Teoria da Autodeterminação e Teoria das Necessidades Psicológicas Básicas}

A Teoria da Autodeterminação (Self-Determination Theory - SDT) surgiu em 1975, a partir da organização do livro Intrinsic Motivation de Edward L. Deci, que abordava os diversos conceitos de motivação intrínseca e argumentava que as pessoas precisariam se sentir autodeterminadas para serem intrinsecamente motivadas (Severo, 2014), a teoria toma forma com a publicação do livro Intrinsic Motivation and SelfDetermination in Human Behavior por Deci juntamente com Richard M. Ryan, em 1985. Ryan (2009) define a Teoria da Autodeterminação da seguinte maneira:

A Teoria da Autodeterminação (SDT) é uma macroteoria da motivação humana, do desenvolvimento da personalidade e do bem-estar. A teoria centra-se especialmente no comportamento volitivo ou autodeterminado e nas condições sociais e culturais que o promovem. A SDT também postula um conjunto de necessidades psicológicas básicas e universais, nomeadas de autonomia, competência e pertencimento, cujo cumprimento é considerado necessário e essencial para o funcionamento humano vital e saudável, independentemente da cultura ou do estágio de desenvolvimento. (p. 1, tradução nossa) $)^{33}$

De acordo com a SDT, é possível diferenciar os tipos de motivação baseando-se nas diversas razões e objetivos que dão início a uma ação. A partir das observações dessas razões, os autores propõem a existência de um continuum de autodeterminação (Ryan \& Deci, 2000), como mostrado na Figura 1; esse continuum é organizado baseando-se nos diferentes tipos de motivação, partindo da desmotivação e passando por quatro tipos de regulação até chegar à motivação intrínseca.

Figura 1. Continuum de Autodeterminação

\section{Continuum de Autodeterminação}

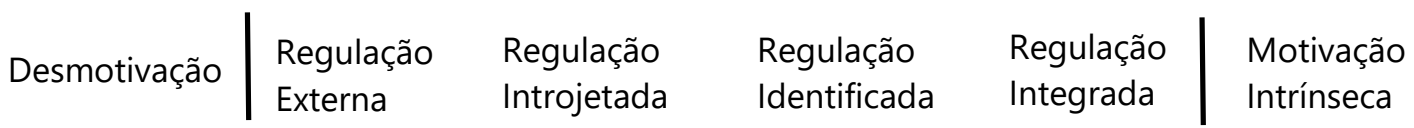

Tipos de Regulações por Motivação

Intrínseca

Conforme as pessoas internalizam e assimilam os regulamentos para si, experimentam maior autonomia no cumprimento das tarefas, esse processo pode ocorrer em etapas, mas não necessariamente como um desenvolvimento contínuo, e sim internalizando um novo comportamento em qualquer ponto ao longo do continuum, dependendo de experiências anteriores e fatores situacionais atuais (Ryan \& Deci, 2000).

3 [Self-determination theory (SDT) is a macro-theory of human motivation, personality development, and well-being. The theory focuses especially on volitional or self-determined behaviour and the social and cultural conditions that promote it. SDT also postulates a set of basic and universal psychological needs, namely those for autonomy, competence and relatedness, the fulfilment of which is considered necessary and essential to vital, healthy human functioning regardless of culture or stage of development]. 
A Teoria das Necessidades Psicológicas Básicas (Basic Psychological Needs Theory - BPNT) trabalha o conceito de necessidades básicas relacionando-as diretamente com o bem-estar (Ryan, 2009). Essa teoria aponta três necessidades psicológicas básicas competência, autonomia e pertencimento - como importantes para a tendência natural dos indivíduos em buscar novidades e desafios para ampliar sua capacidade de aprender.

A competência é a necessidade que as pessoas têm de sentirem-se competentes nos meios sociais e nas interações com outros indivíduos (Appel-Silva et al., 2010). A autonomia mostra a necessidade que os indivíduos têm de ter a oportunidade de escolher as atividades que irão realizar (Cavenaghi, 2009). Por fim, a necessidade de pertencimento explora o papel importante da interação social na realização das tarefas escolhidas pelos indivíduos, é a sensação de sentir-se parte integrante de um grupo (Guimarães \& Boruchovitch, 2004).

Assim, Ryan e Deci (2000) sugerem que o suporte para as necessidades de pertencimento e competência facilita a internalização e o apoio para a necessidade de autonomia facilita a integração da regulação do comportamento; quando isso acontece, as pessoas se sentem competentes, vinculadas e autodeterminadas, sustentando a valorização intrínseca das atividades.

\section{Experimentação no Ensino de Química}

O estudo da Química deve possibilitar aos alunos o desenvolvimento de uma visão crítica do mundo, oferecendo-lhe a oportunidade de conseguir analisar, compreender e utilizar essa visão em seu dia a dia; devemos destacar aqui que o entendimento das razões e objetivos que motivam o ensino da Química poderá ser alcançado se abandonarmos as aulas pautadas na simples memorização de fórmulas e nomes e vinculá-las aos conhecimentos e conceitos do cotidiano do aluno (Cardoso \& Colinvaux, 2000). Contextualizando a Química para o aluno, conseguiremos dar um sentido para seu aprendizado, podendo assim mostrá-la como uma disciplina importante para sua vida e despertando o interesse e curiosidade pelos seus conteúdos.

A experimentação tem a capacidade de desenvolver algumas habilidades pessoais como: motivação, poder de decisão, autoconfiança, capacidade para resolver problemas apresentados, capacidade de comunicação, determinação e etc. De acordo Thomaz (2000), a experimentação pode contribuir na formação de cidadãos capazes de participar das decisões de uma sociedade tecnologicamente avançada e estimular o desenvolvimento intelectual desses cidadãos. A realização de atividades práticas é um importante fator na motivação do aprendizado de Química, pois pode se tornar uma ferramenta bastante eficaz no processo de compreensão dos fenômenos e sua relação com os conceitos científicos envolvidos.

Vale destacar aqui que nem sempre uma atividade experimental é motivadora para os alunos, sendo muitas vezes encarada como monótona e demorada, de acordo com Hodson (1994) "ainda que muitos alunos gostem do tipo de atividades que oferecemos e desenvolvam atitudes positivas em relação à ciência, o mesmo não acontece com um 
bom número deles que expressa sua aversão para o trabalho prático” (p. 300, tradução nossa $)^{44}$. Diante desse aspecto devemos tomar cuidado para que a experimentação não se resuma a uma atividade lúdica ou um simples "espetáculo colorido", mas sim que fique claro seu objetivo como atividade de ensino-aprendizagem. De acordo com as ideias de Vygotski, a motivação e o aprendizado não podem ser dissociados na compreensão dos processos psicológicos, além disso, a motivação e o aprendizado estão diretamente ligados, da mesma forma que o desenvolvimento do pensamento conceitual é fortemente influenciado pelos desejos e emoções, estes também são influenciados pelos conceitos internalizados ao longo da história individual e coletiva (Vygotsky, 1991).

Para termos como objetivo a promoção da motivação dos alunos a partir dos trabalhos experimentais, é preciso que as atividades proporcionadas pelos professores sejam desafiadoras, constituindo um problema que o aluno tenha interesse em resolver e que se sinta, dessa maneira, motivado para encontrar a solução (Thomaz, 2000). A participação ativa dos alunos abre a oportunidade aos "erros" e conduz a discussões importantes para o processo de ensino-aprendizagem, tendo apresentado bons resultados sobre a motivação dos estudantes (Kasseboehmer et al., 2012).

\section{Metodologia}

Considerando o exposto acima e com o intuito de realizar uma pesquisa no âmbito do ensino de Química sobre a importância do processo de escolha, preparação e divulgação de experimentos na motivação dos alunos do Ensino Médio, tornou-se necessária a elaboração de uma questão: "Quais são as contribuições da participação no processo de escolha, preparação e divulgação de experimentos de Química na motivação dos alunos do Ensino Médio?”.

Para responder essa questão foi realizado um estudo com o objetivo principal de entender como esse processo pode influenciar na motivação do aluno, analisando quais fatores, a partir da Teoria da Autodeterminação, motivam os alunos para o estudo da Química, enfatizando o papel da satisfação das necessidades básicas nessa motivação. Para atingir o objetivo principal é preciso primeiramente atingir os objetivos específicos, que são: descrever o perfil motivacional dos alunos antes da realização do processo de escolha, preparação e divulgação dos experimentos; analisar se a realização das atividades favoreceram as necessidades psicológicas básicas; descrever o perfil motivacional dos alunos após a realização do processo de escolha, preparação e divulgação dos experimentos e analisar se houve uma mudança nesse perfil motivacional a partir do continuum da motivação.

A investigação desse trabalho consistiu em uma pesquisa experimental predominantemente qualitativa, pois o interesse dos pesquisadores ao estudarem o problema era verificar como ele se manifesta nas atividades, nos procedimentos e nas

4 [Aunque muchos alumnos disfrutan del tipo de actividades que les ofrecemos en clase y consecuentemente desarrollan actitudes positivas hacia la ciencia, no ocurre lo mismo con um buen número de ellos y hay una importante minoría que expresa su aversión al trabajo práctico]. 
interações cotidianas (Lüdke \& André, 2012).

Segundo Soares e Fazenda (1992) a pesquisa experimental classifica-se como uma pesquisa de intervenção, pois o pesquisador busca modificar a realidade estudada, para isto constrói previamente um plano de pesquisa e o aplica aos grupos de estudo, coletando dados a respeito das possíveis mudanças obtidas. Por isso, a escolha da pesquisa experimental como abordagem metodológica se tornou mais apropriada para nortear o presente estudo, tendo em vista o duplo papel de professora e pesquisadora que um dos autores da pesquisa desempenhou, ao realizá-lo com uma turma de alunos da escola onde leciona.

Para a coleta dos dados foram aplicados dois tipos de questionários: um aberto (QA1 e QA2) e um utilizando a escala Likert (QL1 e QL2). Os questionários QA1 e QL1 foram aplicados antes da realização do processo de escolha, preparação e apresentação dos experimentos; já os questionários QA2 e QL2 foram aplicados depois do processo.

Os questionários utilizando a escala Likert, compostos por 30 questões, tiveram como objetivo a obtenção do perfil motivacional dos alunos. Podemos encontrar na literatura questionários elaborados com o intuito de avaliar os aspectos da motivação no contexto escolar (Boruchovitch et al., 2010) como as escalas EMA (Escala de Motivação Acadêmica) e a WPI (Work Preference Inventory); a escala EMA possui sua confiabilidade determinada pelo Alpha de Cronbach, sendo esse valor igual a 0,80 (valores entre 0,70 e 0,90 indicam que o questionário possui um bom índice de consistência interna), já a escala WPI tem um valor da Alpha de Cronbach igual a 0,82. Para nossa pesquisa, foi necessário elaborar um questionário baseado na EMA e WPI, mas que contemplasse a avaliação da motivação para o estudo da Química levando em consideração as modalidades reguladoras do continuum da motivação. Optou-se por utilizar essas escalas como base pois elas possuem uma boa confiabilidade, o que garantiria, assim, a confiabilidade do questionário utilizado na pesquisa (Neves \& Boruchovitch, 2007). As questões foram divididas da seguinte maneira: desmotivação $(1,7,13,19,25)$, regulação externa $(2,8,14,20,26)$, regulação introjetada $(3,9,15,21,27)$, regulação identificada $(4,10,16,22,28)$, regulação integrada $(5,11,17,23,29)$, motivação intrínseca $(6,12,18$, $24,30)$.

Os questionários abertos contêm 20 questões e tiveram como objetivo analisar se a realização das atividades favoreceu as necessidades psicológicas básicas, esse questionário baseou-se na Basic Need Satisfaction Scale at Work, elaborada por Anja Van den Broeck e colaboradores em 2010 (Van den Broeck et al., 2010). Para essa pesquisa optou-se pela adaptação e aplicação desse questionário de maneira aberta, sem a utilização da escala Likert, pois possibilita a obtenção de dados a partir dos relatos baseados em uma introspecção acurada dos próprios alunos (Boruchovitch et al., 2010). As 20 questões foram divididas em 4 categorias baseadas nas necessidades psicológicas básicas: autonomia (questões 5, 8, 11, 14 e 18), pertencimento (questões 4, 7, 12, 17 e 20), competência (questões 3, 6, 10, 13 e 16) e "outras" (questões 1, 2, 9, 15 e 19); a categoria "outras" continha questões que tinham o objetivo de analisar a relação dos alunos com a disciplina de Química. 
Os questionários foram pré-testados em 30 alunos do Ensino Médio, essa testagem inicial detectou a necessidade de revisão dos instrumentos no que diz respeito a pequenos problemas de linguagem. Após a avaliação dos pesquisadores e a conclusão do pré-teste, desenvolveram-se as versões finais dos questionários que foram usados na pesquisa.

O questionário QL1 foi aplicado no início da coleta de dados, afim de atingir o objetivo especifico de descrever o perfil motivacional dos alunos antes da realização do processo de escolha, preparação e apresentação dos experimentos; já o questionário QL2 foi aplicado ao final da coleta de dados afim de atingir o objetivo especifico de descrever o perfil motivacional dos alunos após a realização desse processo. Os questionários abertos foram aplicados antes (QA1) e depois (QA2) da realização do processo, com o intuito de fazer uma comparação e analisar se esse processo favoreceu as necessidades psicológicas básicas dos alunos. Relacionando os dados de mudança do perfil motivacional com a satisfação das necessidades psicológicas básicas, foi possível compreender como a participação dos alunos nesse processo contribuiu para sua motivação no estudo da Química.

Para a realização da pesquisa foi selecionado um grupo de 13 alunos do $1^{\circ}$ ano do Ensino Médio de uma escola do interior do estado de São Paulo. Os pesquisadores escolheram trabalhar com o $1^{\circ}$ ano do ensino médio por três razões: 1) um dos pesquisadores era, também, professor dessa turma, o que facilitou a observação, comunicação e a interação com os alunos; 2) a maioria dos alunos dessa série é oriunda da escola pública e praticamente não tiveram contato com a experimentação durante o ensino fundamental e 3) era uma turma pequena, com um número de alunos ideal para a realização das práticas laboratoriais e da pesquisa. Assim que a pesquisa foi aprovada pelo Comitê de Ética iniciou-se a coleta de dados, que foi realizada no período de 16 de agosto a 16 de novembro de 2017, foram realizados 8 encontros entre divulgação do projeto e apresentação dos experimentos.

No primeiro encontro foi feita uma apresentação do que seria o trabalho e os alunos foram convidados a participar do projeto. Ainda, nesse momento, foram entregues aos alunos os questionários (QA1 e QL1) para que eles respondessem em casa e devolvessem na semana seguinte; juntamente com os questionários foram entregues os termos de consentimento para serem assinados pelos alunos e responsáveis.

No segundo encontro os grupos foram divididos - era necessário que o projeto fosse realizado em grupos pelo fato de um de seus objetivos ser a busca pela satisfação das necessidades psicológicas básicas e, dentre elas, estar a necessidade de pertencimento que analisa o papel da interação social na realização das tarefas e a sensação de sentir-se parte integrante de um grupo. A escolha dos grupos foi realizada pelos alunos de acordo com a afinidade entre eles.

No terceiro encontro os alunos começaram a escolha e pesquisa dos experimentos que iriam apresentar, para isso, eles foram levados à biblioteca da escola onde havia livros e consulta à internet disponível para auxiliar essa escolha. Durante todo esse processo os 
alunos tiveram autonomia, sendo que os pesquisadores ficaram somente observando e auxiliando quando havia dúvida.

Nos três encontros posteriores aconteceram a realização dos experimentos, sendo realizados no período da tarde (fora do horário de aula); foram utilizados materiais do laboratório da escola e materiais levados pelos pesquisadores. O objetivo desses encontros era a pesquisa, o estudo e o teste dos experimentos para que os alunos se sentissem seguros na hora da apresentação para o público; para que compreendessem bem o procedimento experimental, sanando quaisquer dúvidas sobre ele e para a verificação da possibilidade de realizá-los, pois se necessário fosse haveria tempo para a troca dos experimentos.

No último encontro foi realizada a apresentação dos experimentos para o público, que era formado pelos alunos do $2^{\circ}$ e $3^{\circ}$ anos do Ensino Médio, pelos alunos do curso pré-vestibular e pelos funcionários da escola. Cada um dos quatro grupos apresentou seu trabalho isoladamente, de acordo com a ordem em que os grupos estavam dispostos na bancada do laboratório; todos os integrantes do grupo participaram da apresentação. Durante as apresentações os pesquisadores ficaram observando, após as apresentações os alunos receberam a segunda dupla de questionários (QA2 e QL2) para responder em casa e devolver na semana seguinte. A coleta de dados foi finalizada com a entrega dos questionários devidamente respondidos pelos alunos uma semana após a apresentação.

Os dados obtidos a partir dos questionários foram analisados utilizando o Microsoft Excel para a construção de tabelas e gráficos para a apresentação dos resultados. Utilizou-se, também, na análise dos questionários fechados o cálculo do Ranking Médio (RM), proposto por Oliveira (2005), para a análise dos itens da escala Likert: neste método, atribuiu-se um valor de 1 a 5 para cada resposta do questionário - com esses valores é calculada a média ponderada para cada item, levando em consideração a frequência das respostas. O Ranking Médio foi calculado dividindo a média ponderada pelo número de alunos que responderam ao questionário. A Figura 2 mostra o esquema de como foram feitos os cálculos:

Figura 2. Cálculo do Ranking Médio (RM)

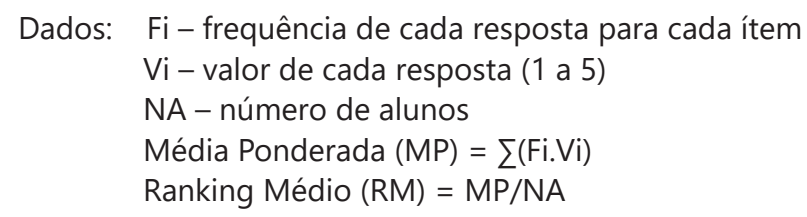

A atribuição realizada foi: não concordo de maneira nenhuma (1), não concordo (2), indiferente (3), concordo (4) e concordo plenamente (5); para a realização da análise foram considerados que os valores obtidos a partir do cálculo do RM inferiores a 3 significam que a importância atribuída a esses fatores foi baixa, valores iguais a 3 mostram uma posição de neutralidade e valores maiores que 3 revelam uma maior valorização dos fatores. 
A análise do perfil motivacional dos alunos foi feita se baseando nos scores obtidos a partir do questionário utilizando a escala Likert; os estudantes respondem à questão assinalando, para cada afirmação, o nível de concordância referente ao motivo que o faz estudar Química. Com base em cada resposta, atribui-se a pontuação correspondente (1 a 5) e somam-se os scores referentes a cada perfil motivacional (Corrêa, 2009). A Figura 3 mostra que os scores mínimos e máximos que podem ser obtidos para cada perfil motivacional são 5 e 25 , sendo 15 a pontuação média.

Figura 3. Intervalos para análise de pontuação

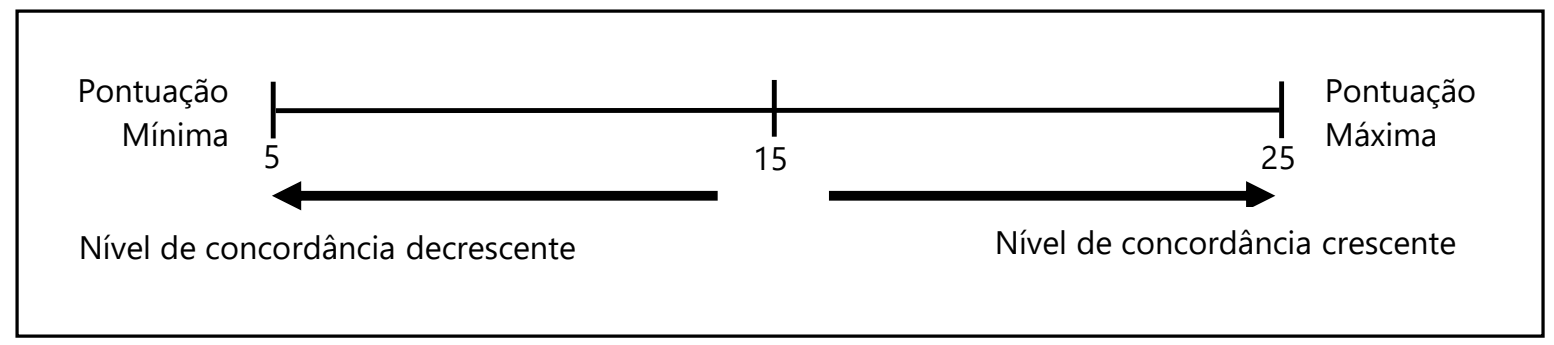

Para a análise dos questionários abertos optou-se por utilizar a Análise de Conteúdo (AC), que consiste em um conjunto de informações e orientações por meio de descrições sistemáticas e objetivas (qualitativas e quantitativas) que ajudam a interpretar o conteúdo das mensagens e atingir a compreensão dos seus significados: a abordagem quantitativa baseia-se na aparição de determinados elementos da mensagem e a qualitativa recorre a elementos não frequentes, suscetíveis de permitir inferências (Bardin, 2009).

\section{Resultados e Discussão}

Por meio dos questionários QL1 e QL2 foi possível fazer uma análise comparativa do perfil motivacional geral dos participantes, antes e depois da realização do projeto. $\mathrm{Na}$ análise desses questionários consideraram-se, para discussão, os valores calculados pelo método do Ranking Médio (RM). Todos os 13 alunos participantes do projeto responderam os questionários de escala Likert.

As Tabelas 1 e 2 apresentam os valores obtidos pelo cálculo do RM para cada nível de motivação a partir da análise dos questionários QL1 e QL2, respectivamente; nas Tabelas as questões estão divididas de acordo com o nível de motivação, mas nos questionários estão embaralhadas, por isso cada nível de motivação apresenta uma numeração desencontrada, não seguindo uma sequência. Foi necessário embaralhar as questões para que as respostas dos alunos não fossem induzidas pelas características de cada uma das questões.

A Tabela 1 fornece os valores do RM para cada questão e a média para o grupo de questões correspondentes ao mesmo perfil motivacional. Para análise dos resultados consideramos o valor mais próximo de cinco como o maior nível motivacional e o mais próximo de um como o menor nível de motivação (Oliveira, 2005). 
Tabela 1. Resultados do cálculo do Ranking Médio do QL1

\begin{tabular}{|c|c|c|c|}
\hline $\begin{array}{l}\text { Perfil } \\
\text { Motivacional }\end{array}$ & Por que você estuda Química? & $\begin{array}{c}\text { Ranking } \\
\text { Médio } \\
\text { (QL1) }\end{array}$ & $\begin{array}{l}\text { Média } \\
\text { do RM } \\
\text { (QL1) }\end{array}$ \\
\hline \multirow{5}{*}{ 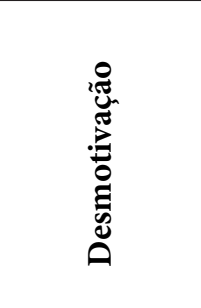 } & 1. Não sei por que vou à aula de química e sinceramente não ligo para isso & 2,1 & \multirow{5}{*}{2,0} \\
\hline & 7. Gostaria que não existissem aulas de química & 1,8 & \\
\hline & 13. Não tenho interesse em entender o que é química & 2,2 & \\
\hline & $\begin{array}{l}\text { 19. Honestamente, não sei, acho que estou perdendo meu tempo nas aulas de } \\
\text { química }\end{array}$ & 1,8 & \\
\hline & 25. Não vejo que diferença faz assistir as aulas de química & 1,9 & \\
\hline \multirow{5}{*}{ 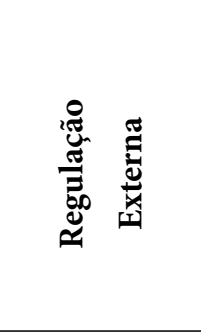 } & $\begin{array}{l}\text { 2. Faço as atividades de química porque a professora dá visto ou porque vale } \\
\text { nota }\end{array}$ & 2,8 & \multirow{5}{*}{3,1} \\
\hline & 8. Estudo química porque meus pais ou responsáveis me mandam vir à escola & 2,9 & \\
\hline & 14. Só estudo química para não reprovar & 3,1 & \\
\hline & 20. Porque quero levar uma boa vida no futuro & 3,2 & \\
\hline & 26. Porque gosto de ficar com meus amigos durante as aulas & 3,4 & \\
\hline \multirow{5}{*}{ 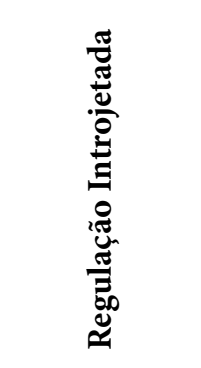 } & 3. Estudo química porque me sinto culpado(a) se não entrego uma atividade & 2,7 & \multirow{5}{*}{3,1} \\
\hline & 9. Estudo química para testar minha inteligência & 3,2 & \\
\hline & $\begin{array}{l}\text { 15. Preciso fazer as tarefas de química para poder entender o conteúdo, senão } \\
\text { não consigo ir bem na prova }\end{array}$ & 3,8 & \\
\hline & $\begin{array}{l}\text { 21. Por causa do fato que me sinto importante quando sou bem sucedido(a) na } \\
\text { escola }\end{array}$ & 3,1 & \\
\hline & 27. Estudo química porque é isso que esperam de mim & 2,6 & \\
\hline \multirow{5}{*}{ 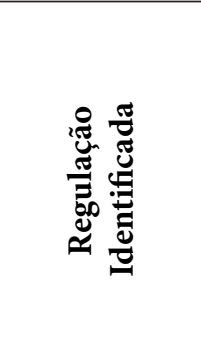 } & $\begin{array}{l}\text { 4. Estudo química porque o diploma de ensino médio pode me ajudar a } \\
\text { conseguir um emprego que pague um salário bom }\end{array}$ & 3,1 & \multirow{5}{*}{3,3} \\
\hline & 10. Estudo química pois ajudará na minha profissão & 2,9 & \\
\hline & 16. Estudo química para passar no vestibular & 3,8 & \\
\hline & 22. Porque me ajudará a escolher melhor minha carreira profissional & 3,5 & \\
\hline & $\begin{array}{l}\text { 28. Porque a frequência e participação nas aulas são necessárias para a } \\
\text { aprendizagem }\end{array}$ & 3,0 & \\
\hline \multirow{5}{*}{ 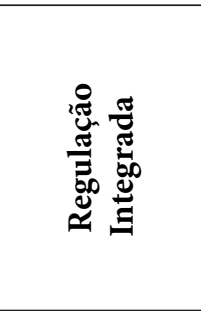 } & 5. Estudo química para melhorar meu conhecimento & 3,7 & \multirow{5}{*}{3,6} \\
\hline & 11. Estudo química para aprender coisas novas e/ou desafiadoras & 3,2 & \\
\hline & 17. Gosto das aulas de química porque o assunto discutido me deixa curioso & 3,7 & \\
\hline & 23. Porque a educação é um privilégio & 3,9 & \\
\hline & 29. Porque estudar amplia os horizontes & 3,7 & \\
\hline \multirow{5}{*}{ 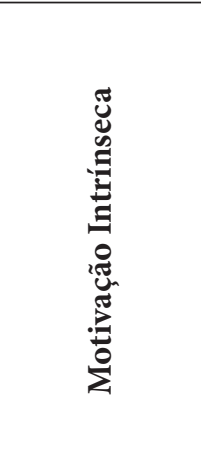 } & $\begin{array}{l}\text { 6. Estudo química pelos momentos de satisfação que experimento quando falo } \\
\text { das minhas ideias para a turma }\end{array}$ & 2,6 & \multirow{5}{*}{3,1} \\
\hline & $\begin{array}{l}\text { 12. Estudo química pela satisfação que sinto ao descobrir coisas que nunca } \\
\text { tinha visto antes }\end{array}$ & 3,4 & \\
\hline & $\begin{array}{l}\text { 18. Estudo química pela satisfação que sinto quando estou completamente } \\
\text { envolvido com o conteúdo apresentado na sala de aula }\end{array}$ & 3,2 & \\
\hline & 24. Porque para mim estudar é um prazer & 2,5 & \\
\hline & $\begin{array}{l}\text { 30. Pelo prazer que tenho em ampliar meu conhecimento sobre assuntos que } \\
\text { me atraem }\end{array}$ & 3,8 & \\
\hline
\end{tabular}


Podemos observar que o maior valor obtido foi para Regulação Integrada $(3,6)$, mostrando que a maior parte dos alunos apresenta interesse pelas aulas de Química, esse interesse não é somente fruto de recompensas externas, é também proveniente da importância que atribuem à aprendizagem e ao estudo; as questões 5 e 17 ilustram essa importância, pois a maioria dos alunos afirma que gosta das aulas de Química e que estas contribuem para a melhoria do conhecimento, apresentando valores altos de RM $(3,7)$ para esse perfil motivacional.

Observamos também um baixo valor obtido para a Desmotivação $(2,0)$, sendo que a diferença entre esse valor e o da Regulação Integrada é expressiva, isso nos mostra que o desinteresse pelas aulas de Química é pequeno e contraria o senso comum que afirma que os alunos são desinteressados pelos estudos. Segundo Brophy (1983), um aluno não necessariamente é desmotivado para tudo na sala de aula, ele pode estar desmotivado apenas em alguns conteúdos, por isso não podemos afirmar que um aluno é desmotivado para as aulas de Química, já que os resultados mostram que para esse grupo de alunos a desmotivação foi baixa.

Outro aspecto que podemos destacar é o crescimento dos valores do RM da Desmotivação $(2,0)$ até a Regulação Integrada $(3,6)$ e após esse nível um decréscimo até a Motivação Intrínseca $(3,1)$. Esse declínio da Regulação Integrada para a Motivação Intrínseca mostra que o desenvolvimento desse perfil motivacional nos alunos não é algo simples; para um indivíduo apresentar o perfil da Motivação Intrínseca as três necessidades psicológicas básicas devem ser supridas ao mesmo tempo (Ryan \& Deci, 2000), mas a maioria das escolas, inclusive a presente neste trabalho, não consegue apresentar um ambiente que satisfaça essas necessidades, tornando difícil a obtenção da Motivação Intrínseca.

Analisaremos, agora, os dados obtidos a partir das respostas do questionário de escala Likert aplicado após a realização do projeto. Na Tabela 2 são apresentados os valores obtidos pelo cálculo do Ranking Médio para cada nível de motivação a partir da análise do QL2.

De acordo com a Tabela 2 observamos que o maior valor de RM obtido corresponde também à Regulação Integrada $(3,6)$, sendo esse valor igual ao obtido na análise do QL1. A partir desse resultado poderíamos pensar que não houve nenhuma mudança no perfil motivacional dos alunos, mas se analisarmos a Tabela 2 com mais atenção perceberemos que houve um aumento no valor do RM da Motivação Intrínseca (inicialmente 3,1 e posteriormente 3,4) e uma diminuição no valor da Desmotivação (inicialmente 2,0 e posteriormente 1,2), ou seja, os alunos caminharam, após a realização do projeto, em direção a um comportamento intrinsecamente motivado no continuum da motivação. 
Tabela 2. Resultados do cálculo do Ranking Médio do QL2

\begin{tabular}{|c|c|c|c|c|}
\hline $\begin{array}{l}\text { Perfil } \\
\text { Motivacional }\end{array}$ & Por que você estuda Química? & $\begin{array}{c}\text { Ranking } \\
\text { Médio } \\
\text { (QL2) }\end{array}$ & $\begin{array}{c}\text { Média } \\
\text { do RM } \\
\text { (QL1) }\end{array}$ & $\begin{array}{c}\text { Média } \\
\text { do RM } \\
\text { (QL2) }\end{array}$ \\
\hline \multirow{5}{*}{ 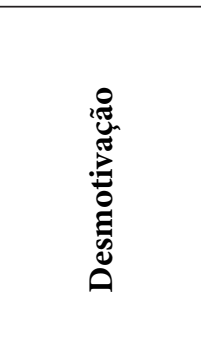 } & 6. Não vejo que diferença faz assistir as aulas de química & 1,2 & \multirow{5}{*}{2,0} & \multirow{5}{*}{1,2} \\
\hline & $\begin{array}{l}\text { 12. Honestamente, não sei, acho que estou perdendo meu tempo } \\
\text { nas aulas de química }\end{array}$ & 1,5 & & \\
\hline & 18. Não tenho interesse em entender o que é química & 1,3 & & \\
\hline & 24. Gostaria que não existissem aulas de química & 1,1 & & \\
\hline & $\begin{array}{l}\text { 30. Não sei por que vou à aula de química e sinceramente não ligo } \\
\text { para isso }\end{array}$ & 1,2 & & \\
\hline \multirow{5}{*}{ 胥 } & 5. Ficar com meus amigos durante as aulas & 2,8 & \multirow{5}{*}{3,1} & \multirow{5}{*}{2,7} \\
\hline & 11. Quero levar uma boa vida no futuro & 3,2 & & \\
\hline & 17. Não reprovar & 2,0 & & \\
\hline & 23. Meus pais ou responsáveis me mandam vir à escola & 2,8 & & \\
\hline & $\begin{array}{l}\text { 29. Faço as atividades de química porque a professora dá visto ou } \\
\text { porque vale nota }\end{array}$ & 2,6 & & \\
\hline \multirow{5}{*}{ 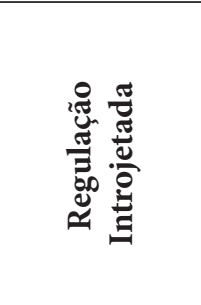 } & 4. É isso que esperam de $\mathrm{mim}$ & 2,8 & \multirow{5}{*}{3,1} & \multirow{5}{*}{2,8} \\
\hline & 10. Sinto-me importante quando sou bem sucedido(a) na escola & 3,0 & & \\
\hline & $\begin{array}{l}\text { 16. Preciso fazer as tarefas de química para poder entender o } \\
\text { conteúdo, senão não consigo ir bem na prova }\end{array}$ & 3,1 & & \\
\hline & 22. Testar minha inteligência & 3,0 & & \\
\hline & 28. Sinto-me culpado(a) se não entrego uma atividade & 2,1 & & \\
\hline \multirow{5}{*}{ 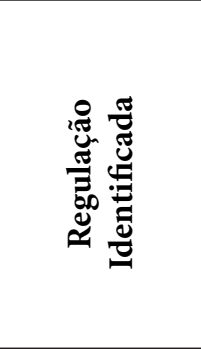 } & $\begin{array}{l}\text { 3. A frequência e participação nas aulas são necessárias para a } \\
\text { aprendizagem }\end{array}$ & 3,2 & \multirow{5}{*}{3,3} & \multirow{5}{*}{3,2} \\
\hline & 9. Me ajudará a escolher melhor minha carreira profissional & 3,1 & & \\
\hline & 15. Passar no vestibular & 3,4 & & \\
\hline & 21. Ajudará na minha profissão & 2,8 & & \\
\hline & $\begin{array}{l}\text { 27. O diploma de ensino médio pode me ajudar a conseguir um } \\
\text { emprego que pague um salário bom }\end{array}$ & 3,5 & & \\
\hline \multirow{5}{*}{ 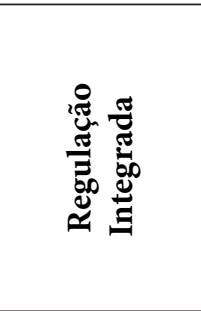 } & 2. Estudar amplia os horizontes & 3,5 & \multirow{5}{*}{3,6} & \multirow{5}{*}{3,6} \\
\hline & 8. Educação é um privilégio & 3,5 & & \\
\hline & $\begin{array}{l}\text { 14. Gosto das aulas de química, porque o assunto discutido me } \\
\text { deixa curioso }\end{array}$ & 3,7 & & \\
\hline & 20. Aprender coisas novas e/ou desafiadoras & 3,5 & & \\
\hline & 26. Melhorar meu conhecimento & 3,7 & & \\
\hline \multirow{5}{*}{ 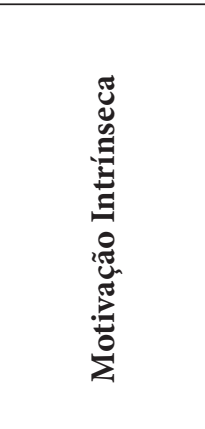 } & $\begin{array}{l}\text { 1. O prazer que tenho em ampliar meu conhecimento sobre } \\
\text { assuntos que me atraem }\end{array}$ & 3,5 & \multirow{5}{*}{3,1} & \multirow{5}{*}{3,4} \\
\hline & 7. Estudar é um prazer & 3,1 & & \\
\hline & $\begin{array}{l}\text { 13. A satisfação que sinto quando estou completamente envolvido } \\
\text { com o conteúdo apresentado na sala de aula }\end{array}$ & 3,5 & & \\
\hline & $\begin{array}{l}\text { 19. A satisfação que sinto ao descobrir coisas que nunca tinha } \\
\text { visto antes }\end{array}$ & 3,5 & & \\
\hline & $\begin{array}{l}\text { 25. Os momentos de satisfação que experimento quando falo das } \\
\text { minhas ideias para a turma }\end{array}$ & 3,6 & & \\
\hline
\end{tabular}


A Figura 4 mostra a comparação entre os valores do RM para cada perfil motivacional antes e depois da realização do projeto.

Figura 4. Comparação dos valores do RM

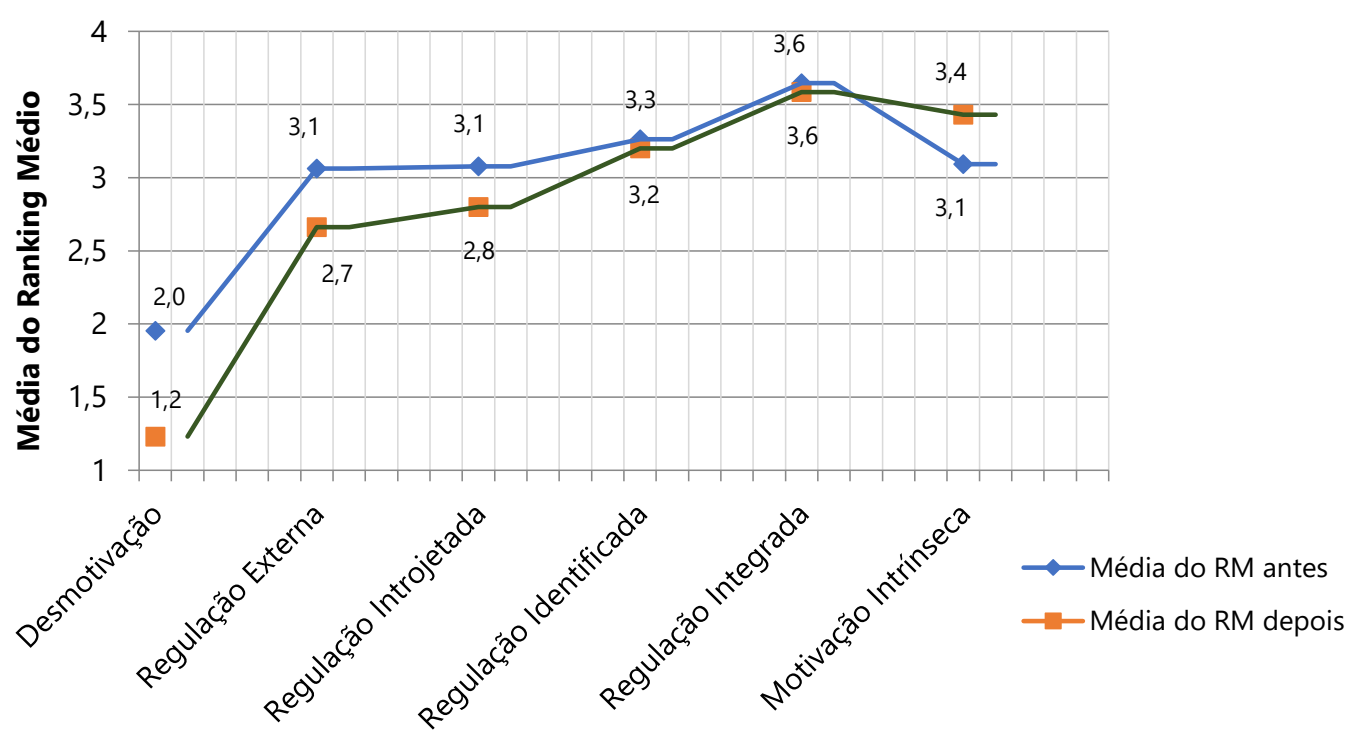

O gráfico deixa clara a mudança que aconteceu nos valores do RM antes e depois da realização do projeto; os valores referentes à Desmotivação e a Regulação Externa, formas menos autodeterminadas de motivação, tiveram uma queda significativa, e o valor referente à Motivação Intrínseca, forma mais autodeterminada de motivação, teve um aumento, levando-nos a concluir que os alunos se sentiram mais motivados para o estudo da Química após a participação no projeto.

Não devemos achar que o projeto não obteve sucesso pelo fato de não alcançarmos a Motivação Intrínseca. Como dito anteriormente, o desenvolvimento desse perfil motivacional nos alunos não é simples, Boruchovitch e Bzuneck (2000) afirma que a motivação dos alunos não é intrínseca, e este fato não deve causar surpresa, visto que a escola, de modo geral, não prioriza essa orientação, pois preocupa-se, na maior parte do tempo, com a transmissão de conteúdos e a avaliação do desempenho através de notas, dando ênfase aos motivadores extrínsecos.

Os questionários QA1 e QA2 apresentam informações importantes sobre a avaliação da satisfação das necessidades básicas dos alunos antes e depois da realização do projeto. Na análise dos questionários de cada aluno utilizaram-se, para a discussão, as categorias obtidas a partir da Análise de Conteúdo (AC). Todos os 13 alunos participantes responderam ao questionário aberto (1), mas apenas 8 responderam ao questionário aberto (2), nesse caso utilizaram-se apenas os dados dos 8 alunos respondentes, sendo descartados os questionários abertos (1) dos outros 5 alunos. Esses 8 alunos respondentes serão identificados por ordem numérica, sendo aluno 1 (A1), aluno 2 (A2), aluno 3 (A3) 
e assim até o aluno 8 (A8).

A partir da análise do questionário QA1, observamos que os alunos não se sentem capazes para desempenhar atividades experimentais sozinhos, principalmente se precisarem apresentá-las ao público; quando não há o envolvimento de atividades experimentais ou a presença do público, os alunos julgam-se capazes para desempenhar as tarefas, sem contar que explicar um conteúdo para alguém que você conheça e que tenha as mesmas dificuldades que você, proporciona uma maior sensação de segurança do que apresentar um trabalho para pessoas desconhecidas. Podemos concluir, a partir dos dados obtidos, que a necessidade psicológica básica de competência não está sendo completamente satisfeita, pois os alunos não estão sentindo-se eficazes para poder exercitar suas capacidades; de acordo com Cavenaghi (2009), "a competência é a necessidade de ser eficaz nas interações com o ambiente, refletindo o desejo natural de exercitar as próprias capacidades na busca de vencer desafios" (p. 255).

A partir da análise geral do questionário QA2 observamos um aumento na satisfação da necessidade de competência. Na questão 3 os alunos afirmam não possuírem dificuldades ou problemas nas aulas de Química, essa resposta confirma os dados obtidos na análise do primeiro questionário, que a turma não apresenta grandes dificuldades de aprendizagem durante as aulas e durante os processos avaliativos. Essa postura dos alunos mostra que eles possuem um envolvimento com a disciplina, pois se dedicam ao estudo da mesma, há uma qualidade nesse envolvimento, pois mais importante que a intensidade do esforço é o seu direcionamento, ou seja, no que o aluno realmente investe seu tempo e capacidades durante a realização das atividades (Accorsi et al., 2007).

A questão 10 já começa a mostrar um resultado expressivo da satisfação da necessidade de competência, no QA1 dos 8 alunos participantes 5 responderam que não se sentiam capazes para apresentar um experimento, mas após a realização do projeto, 6 alunos afirmaram que se sentiram capazes para apresentar os experimentos; podemos perceber que durante a escolha e preparação dos experimentos os alunos compreenderam que a realização de um experimento não é algo complexo, que eles puderam escolher atividades que estivessem ao seu alcance e compatíveis com suas habilidades, desenvolvendo um sentimento de competência para a apresentação desses experimentos; a comparação das falas do aluno 4 antes e depois da apresentação dos experimentos mostra essa diferença.

Aluno $4-\mathrm{A} 4$

QA1: "Não, por vergonha, timidez e por ser introvertido"

QA2: "Sim, porque estava mais confiante de mim mesmo"

Podemos destacar também a fala de outro aluno, afirmando que após a preparação e estudo se sentiu capaz para apresentar o experimento.

Aluno 5 - A5

QA1: "Não, porque eu não me acho capaz"

QA2: "Sim, porque eu achei que assim eu perdi a vergonha de falar em público" 
Essa experiência - relatada pelos alunos $4 \mathrm{e} 5$ - de dominar uma tarefa desafiadora e o aumento da competência dela resultante trazem emoções positivas, denominadas de 'sentimento de eficácia' e segundo Boruchovitch e Bzuneck (2000), para promovê-lo a tarefa solicitada deve conter metas claras e significativas, cuja obtenção exija esforço, as tarefas devem ter um 'nível ótimo', ou seja, as pessoas devem ser capazes de se envolver em uma tarefa cujo grau de dificuldade encontra-se no nível de suas habilidades, dessa maneira a pessoa se sente competente.

Podemos observar que, no geral, o projeto despertou a necessidade básica de competência dos alunos, principalmente em relação à apresentação dos experimentos para o público, pois conseguiram enxergar uma maneira diferente de realizar uma atividade experimental, livre de roteiros, das ordens do professor e da pressão de avaliações (Appel-Silva et al., 2010).

Faremos agora uma análise das questões dos questionários abertos $(1 \mathrm{e} 2)$ referentes à necessidade básica pertencimento. A análise do questionário QA1 nos mostra que, no geral, a turma não possui dificuldades de relacionamento, sempre trabalhando bem em grupo. Aparentemente a necessidade psicológica básica de pertencimento está sendo satisfeita durante as aulas, sempre promovendo as atividades em grupo, de modo que todos os alunos se sintam parte integrante da turma.

A questão 4 do questionário QA2 mostra que durante a realização do projeto os alunos preferiram trabalhar em grupo, confirmando o que eles já haviam respondido anteriormente. Durante os encontros os grupos trabalharam sem problemas, todos os integrantes desempenharam suas funções, todos participaram das atividades, da pesquisa, do estudo e da realização dos experimentos. Não houve nenhuma reclamação, por parte dos alunos sobre algum integrante do grupo, pelo contrário, eles alegam que o trabalho em grupo foi bastante produtivo e que todos ajudaram a entender o que deveria ser feito. Podemos observar essa preferência pelo trabalho em grupo nas falas dos alunos antes e depois da realização dos experimentos.

Aluno 6 - A6

QA1: "Grupo pois é mais fácil formular respostas"

QA2: "Gostei de trabalhar em grupo pois recebi uma boa ajuda"

Aluno $8-$ A8

QA1: "Em grupo, porque a matéria pode ficar mais divertida e interessante"

QA2: "Em grupo, sinto que teve mais dinâmica"

As questões 7, 12, 17 e 20 apresentaram praticamente os mesmos resultados apresentados anteriormente, o que reforça a ideia de que a necessidade de pertencimento vem sendo satisfeita durante as aulas e durante o projeto. Esse resultado também pode ser fruto do pouco tempo transcorrido entre a aplicação dos dois questionários, apenas 3 meses, nesse pouco tempo a rotina escolar e familiar dos alunos não sofreu mudanças expressivas, os amigos continuam os mesmos e a relação com a família também.

Questão 7 - A5

QA1: "Juntos, porque ele pode tirar minhas dúvidas e eu as deles" 


\section{QA2: "Estudar com amigos, porque assim vejo no que estou errando"}

Questão $20-\mathrm{A} 1$

QA1: "Ficar em casa com minha família"

QA2: "Ficar com minha família"

Segundo Ryan e Deci (2000), para que a necessidade de pertencimento seja atendida, a pessoa precisa perceber que há um desenvolvimento de conexões seguras do grupo em relação a ela e um genuíno apoio às dificuldades dela, seja no contexto familiar, do trabalho, do lazer, etc. $\mathrm{O}$ trabalho em grupo e a colaboração entre os alunos durante a resolução de um problema são peças-chave da teoria de Vygotsky (1991), pois é por meio do outro que o indivíduo se forma, isto é, consegue internalizar os conceitos socialmente compartilhados e desenvolve suas funções psicológicas complexas. Não podemos deixar de lado atividades que proporcionem interação e troca de conhecimentos entre os alunos, pois essas atividades garantem a motivação e a cooperação para aprender.

Faremos agora uma análise das questões dos questionários abertos ( 1 e 2) referentes à necessidade básica autonomia. Observando os resultados do questionário QA1, podemos dizer que os alunos não se sentem autônomos dentro do laboratório, pois necessitam sempre de um roteiro ou de instruções do professor.

A pequena diferença entre os questionários inicial e final fica perceptível na fala de um aluno, que disse no primeiro momento que não gostava de liderar e após a realização do projeto afirmou que o trabalho foi em realizado em grupo, sem uma liderança específica.

Aluno 6 - A6

QA1: "Prefiro que alguém lidere, pois sou desorganizado"

QA2: "Fizemos em conjunto, para trabalhar em equipe"

$\mathrm{Na}$ questão 8 já podemos observar uma mudança significativa na postura dos alunos em relação ao laboratório; no primeiro questionário a maioria afirmou que preferia que o professor realizasse o experimento primeiro e eles reproduzissem depois, após a realização do projeto a preferência pela ausência do professor foi unânime, todos os 8 participantes afirmaram que preferiram realizar o experimento somente com o grupo. As questões 11 e 14 confirmam essa mudança de postura, os alunos passaram a preferir fazer as atividades de laboratório somente entre eles, e sem a necessidade de um roteiro, ficando livres para pesquisar e escolher o experimento; eles justificam essa preferência dizendo que quando fizeram as atividades sozinhos tiveram mais liberdade, independência e conseguiram aprender melhor o conteúdo envolvido no experimento.

Questão 8:

Aluno 1 - A1

QA1: "Prefiro que o professor realize primeiro para entender o processo primeiro"

QA2: "Preferi fazer somente com o grupo, pois tivemos mais liberdade e independência" 


\section{Questão 14:}

Aluno 7 - A7

QA1: "Escolher com a ajuda do professor para não fazer nada errado"

QA2: "Quando ficamos livres, pois sinto que aprendemos bem quando fazemos sozinhos"

No geral podemos afirmar que a necessidade psicológica de autonomia foi satisfeita nesse projeto, pois podemos enxergar claramente a mudança de postura dos alunos em relação às atividades experimentais, aonde no início praticamente todos se sentiam inseguros, necessitando de roteiros e acompanhamento direto do professor, mas após a realização do projeto conseguiram compreender que quando têm liberdade para escolher o que irão fazer aprendem melhor. De acordo com Cavenaghi (2009), os estudantes autônomos tornam-se altamente motivados, e essa autonomia conduz a uma melhoria significativa da aprendizagem, pois o aluno tem um controle pessoal diante da aprendizagem e se responsabiliza por ela, dessa forma a autonomia se refere às escolhas que os alunos fazem em relação à quais atividades eles irão se aproximar ou evitar, e o grau de esforço empregado na realização dessas atividades.

Pensando nos resultados obtidos, podemos dizer que no geral não houve uma grande mudança no perfil motivacional dos alunos após a realização do projeto, porém entendemos que há uma tendência a mudança do perfil motivacional dos alunos, o que é comprovado pela análise da Figura 4 (Comparação dos valores do RM), que mostra um aumento nos valores do RM para as formas mais autodeterminadas da motivação e um decréscimo para os valores da Desmotivação, confirmando que os alunos estão caminhando para a Motivação Intrínseca.

Uma mudança na orientação motivacional de todos os alunos é algo praticamente impossível de ser obtido, pois a promoção da motivação depende de vários fatores que ocorrem na escola como um todo e na vida familiar dos alunos, sendo a atividade desenvolvida e o papel do professor apenas dois entre esses vários aspectos (Severo, 2014).

O tipo de atividade realizada também foi eficiente na satisfação das necessidades básicas; o processo de escolha, preparação e apresentação dos experimentos conseguiu despertar a competência e a autonomia dos alunos, mostrando que esse tipo de abordagem pode ser um importante promotor da motivação intrínseca. Ao analisar o papel da experimentação na construção do conhecimento científico e sua relevância no processo de ensino-aprendizagem, Giordan (1999) observou que a experimentação desperta um forte interesse entre os alunos, que atribuem a esta um caráter motivador, lúdico e essencialmente vinculado aos sentidos, contribuindo assim para uma melhora na motivação pela aprendizagem dos conhecimentos das aulas de Química. No entanto, devemos tomar cuidado para a experimentação não representar apenas um momento de descontração que nada tenha a ver com a aquisição de conhecimento; para que essa abordagem seja eficiente na promoção da motivação é necessário que seus objetivos 
sejam claros, suas atividades desafiadoras e que o problema a ser resolvido desperte o interesse do aluno, para que assim se sinta motivado para encontrar a solução; no caso das atividades desenvolvidas durante o projeto, elas não se reduziram à simples participação do aluno, mas foram planejadas para fazerem parte de um contexto mais amplo, incluindo outros aspectos do currículo e principalmente a satisfação das necessidades básicas (Gonçalves, 2005).

Observamos que a satisfação das necessidades psicológicas básicas está diretamente relacionada com o aumento e a permanência da motivação dos alunos, isso nos mostra que contextos que dão suporte à competência, pertencimento e autonomia podem promover uma maior internalização e integração dos comportamentos, levando à uma promoção da motivação, enquanto que contextos que impedem a satisfação dessas necessidades não favorecem a valorização intrínseca das atividades (Ryan \& Deci, 2000).

$\mathrm{Na}$ Teoria da Autodeterminação - referencial teórico utilizado nessa pesquisa - as necessidades sociais que surgem das experiências pessoais dependem do tipo e da qualidade da interação com o ambiente social que cada aluno estabelece; essas interações devem contribuir para o desenvolvimento das três necessidades psicológicas básicas destacadas pela teoria: competência, autonomia e pertencimento. Pensando nessa contribuição, Boruchovitch e Bzuneck (2000) ressaltam a importância de se criar ambientes favoráveis ao desenvolvimento da aprendizagem autorregulada, proporcionando aos alunos competências e condições para regular, dirigir e controlar a sua própria aprendizagem, o que envolve o controle das emoções, do investimento de esforço, do grau de motivação e do uso adequado de estratégias de aprendizagem. Ainda pensando no desenvolvimento das necessidades psicológicas básicas, podemos citar as contribuições de Vygotsky (1991), que ressalta que tarefas entediantes e sem apelo à motivação, isto é, aquelas que não levam em conta os interesses dos alunos, tendem a ser assimiladas com mais dificuldade; no entanto, as tarefas que vão ao encontro dos interesses dos alunos e atendem sua realidade, como as realizadas nesse trabalho, são realizadas de maneira prazerosa, levando-os a participarem mais e possibilitando uma aprendizagem efetiva.

Vygotsky se dedicou ao estudo da origem social das funções psicológicas superiores, que são modos de funcionamento psicológicos "mais sofisticados", tais como a capacidade de planejamento, memória voluntária, imaginação e pensamento abstrato. Durante a pesquisa os alunos precisaram escolher, preparar e apresentar os experimentos; esse processo pode colaborar com o desenvolvimento das funções psicológicas superiores, já que essas são construídas nas relações do indivíduo em seu contexto social, e se desenvolvem por meio dos processos de internalização das formas culturais de comportamento (Vygotsky, 1991).

A necessidade de pertencimento, considerada por Deci e Ryan (1985) como uma das mais importantes para fixar a autodeterminação como fator principal da motivação, pode ser suprida na relação do aluno com o professor, que atua como mediador, e também na relação com os colegas durante um trabalho em grupo. Durante a atividade experimental o aluno estabelece uma relação dialética com seus pares, onde é capaz 
de desenvolver e potencializar sua percepção, organizar os elementos percebidos, compreender os significados da atividade e desenvolver funções psicológicas cada vez mais sofisticadas.

Vygotsky destaca também que a busca para a solução de problemas durante uma atividade é um fator que se faz necessário para o processo de formação de conceitos, dessa forma, se o ambiente não apresenta nenhuma dessas tarefas ao adolescente, não lhe faz novas exigências e não estimula seu intelecto, proporcionando-lhe uma série de novos objetos, o seu raciocínio não conseguirá atingir os estágios mais elevados, ou só os alcançará com grande atraso (Vygotsky, 1991). Essa busca para a solução de problemas durante uma atividade também contribui para o desenvolvimento das necessidades de competência e autonomia do aluno, pois frente a um desafio o aluno pode sentir-se capaz e estimulado, principalmente durante a interação com o professor e os colegas, Oliveira (2010) ressalta que:

[...] a importância das atividades experimentais tem sido bastante ressaltada devido ao fato de colocarem os alunos como sujeitos ativos nas várias etapas de resolução de um problema que envolva um processo experimental; esse tipo de atividade, apesar da complexidade e do tempo que costuma demandar, pode ser considerada, na perspectiva de Vygotsky, uma tarefa desafiadora, que faz novas exigências ao estudante e que, por esse motivo, estimula seu intelecto a evoluir para níveis mais elevados, ao mesmo tempo em que atua diretamente na motivação do aluno. (p. 16)

Quando as atividades experimentais são desenvolvidas buscando suprir as três necessidades psicológicas básicas, ou seja, com o trabalho realizado em grupos, tendo o professor como mediador e o aluno decidindo quais tarefas irá realizar e conduzindo ele próprio o processo de ensino-aprendizagem, a valorização da dialética pessoa/ambiente representa a integração entre o contexto social e o desenvolvimento das funções psicológicas complexas; cada indivíduo passa a agir em função da motivação intrínseca por buscar e promover alterações no ambiente e, por outro lado, o ambiente apresenta demanda às pessoas, para que elas se ajustem e se acomodem a ele.

Uma das contribuições fundamentais dessa perspectiva relaciona-se com a concepção do processo de conhecimento como produção simbólica e material que se estabelece na dinâmica das interações entre as pessoas. Neste sentido, o foco das atenções na sala de aula não estaria no professor, nos alunos ou no conteúdo, mas sim no movimento das interações que ocorrem ao longo do processo. Nesse movimento interativo, a atividade cognitiva dos sujeitos vai sendo constituída através do outro e através da linguagem. (Boruchovitch \& Bzuneck, 2000, p. 27)

Pensando nesses aspectos mencionados acima e buscando garantir o desenvolvimento das necessidades psicológicas básicas, todo trabalho foi realizado em grupos com o professor atuando apenas como mediador, os alunos tiveram toda a liberdade para escolher os conteúdos que foram abordados e os experimentos que foram 
realizados, eles próprios propuseram maneiras de realizar os experimentos e a melhor forma de apresenta-los para o público. Todo o processo teve o aluno como sujeito principal, para que as necessidades psicológicas básicas fossem supridas e a motivação intrínseca fosse estimulada a partir da autodeterminação. O trabalho em grupo e a colaboração entre os alunos durante a resolução de um problema são peças-chave da teoria de Vygotsky, pois é por meio do outro que o indivíduo se forma, isto é, consegue internalizar os conceitos socialmente compartilhados e desenvolve suas funções psicológicas complexas. Não podemos deixar de lado atividades que proporcionem interação e troca de conhecimentos entre os alunos, pois essas atividades garantem a motivação e a cooperação para aprender (Oliveira, 2010).

Dentro do objetivo de compreender o desenvolvimento das funções psicológicas complexas, Vygotsky dá importância especial à aprendizagem, considerando-a necessária para o desenvolvimento das características humanas. Para ele, a aprendizagem não é, em si mesma, desenvolvimento, mas se adequadamente motivada, conduz ao desenvolvimento, já que ativa diversos processos mentais que do contrário não seriam ativados.

Observamos, então, que a motivação e o aprendizado não podem ser dissociados na compreensão dos processos psicológicos, além disso, a motivação e o aprendizado estão diretamente ligados, da mesma forma que o desenvolvimento do pensamento conceitual é fortemente influenciado pelos desejos e emoções, estes também são influenciados pelos conceitos internalizados ao longo da história individual e coletiva. Assim, na perspectiva de Vygotsky a escola deve aumentar seus esforços para a promoção da motivação dos alunos, buscando estimular e ativar os recursos cognitivos, ou seja, a motivação deve ser tida como essencial no processo de aprendizagem.

Esse estudo fornece um conjunto de dados sobre características motivacionais importantes obtidas a partir de instrumentos utilizados em pesquisas internacionais recentes, porém ainda são escassos os trabalhos sobre essa temática, em especial no Ensino de Química, no cenário nacional. Os resultados obtidos reforçam outros da literatura (Boruchovitch et al., 2010; Cardoso \& Colinvaux, 2000; Kasseboehmer et al., 2012), que apontam que o estudo da motivação nessa área é importante tanto para melhor compreender de que maneira as necessidades psicológicas básicas dos alunos podem ser supridas, quanto para compreender como esse conhecimento pode ser utilizado para que os professores consigam perceber a motivação dos seus alunos (Corrêa, 2009).

Os questionários utilizados neste trabalho mostraram-se úteis para traçar o perfil motivacional de alunos para o estudo da Química e podem ser utilizados para analisar a contribuição de diferentes estratégias didáticas para desenvolver a motivação para a aprendizagem. Os questionários também podem ser adaptados para traçar o perfil motivacional de estudantes em outras áreas de conhecimento. Por isso, pensamos que esse trabalho pode despertar a ocorrência de novos estudos para se compreender como influenciar positivamente na motivação dos alunos e o que pode ser feito para tornar o estudante mais autônomo e, assim, aprender melhor. O estudo da motivação é um tema de grande relevância para a compreensão e manutenção do comportamento dos alunos 
em sala de aula, por isso esse estudo apresenta relevância para profissionais que querem entender e melhorar a motivação de seus alunos.

A partir dos resultados apresentados nesse estudo, podemos sugerir que as escolas desenvolvam políticas e práticas que busquem a promoção da motivação para que, assim, possam proporcionar maiores resultados educacionais. Em face desse resultado verificase que é possível resgatar essa percepção positiva para, consequentemente, desenvolver estratégias de ensino que possam contribuir para que os alunos sintam interesse pelo ensino de química nas escolas de educação básica (Cernev \& Hentschke, 2012).

O contato dos professores da educação básica com o conhecimento divulgado na literatura sobre a relação entre experimentação e motivação é uma oportunidade para esses professores se apropriarem do discurso sobra a natureza pedagógica das atividades experimentais. Essa apropriação poderá contribuir para a fundamentação e análise do exercício da docência e também para a realização de uma leitura crítica da utilização das práticas experimentais (Gonçalves, 2005).

Portanto, os resultados apresentados nesta pesquisa podem trazer contribuições substanciais ao ensino de Química, na medida em que destacam a importância de que o professor conheça os processos de motivação e sua relevância em sala de aula. Pois, no ambiente escolar, o estudante pode ter seu comportamento regulado por diversos fatores, como influências sociais, pressões internas, frequências ou, ainda, ser impelido a comparecer às aulas em busca de interações. Conhecendo as motivações dos estudantes, professores e instituições podem atuar no sentido de estimulá-los e mantê-los motivados para o estudo da Química.

\section{Conclusões e Implicações}

A partir da análise realizada acima podemos observar que houve uma mudança no perfil motivacional da turma, pois o valor do RM apresentou um aumento para as formas mais autodeterminadas de motivação e uma diminuição para a Desmotivação, mostrando que a turma está caminhando da Regulação Integrada para a Motivação Intrínseca, e a razão principal dessa mudança é a satisfação das necessidades psicológicas básicas dos alunos; conseguimos observar nas falas que houve uma satisfação, principalmente, das necessidades de competência e autonomia, pois os alunos mostraram sentirem-se cada vez mais capazes e autônomos para a realização das atividades durante o andamento do projeto. Observamos que a motivação é um constructo importante para a aprendizagem dos alunos e está diretamente ligada à qualidade do desempenho na realização das atividades escolares. Durante a realização da pesquisa, o contexto em que os alunos foram inseridos influenciaram diretamente seu nível motivacional, por isso, a relação do professor com os alunos, o ambiente, os trabalhos em grupo, a utilização de atividades desafiadoras, entre outros fatores, contribuíram para a motivação dos estudantes (Pozo \& Crespo, 2009).

Como podemos observar em todo processo educativo, émuito difícil uma atividade atingir todos os participantes, todavia, foi possível verificar a partir dos resultados que 
o alcance desse projeto foi significativo. Mesmo notando avanços no perfil motivacional dos alunos, é necessário mencionar que várias dificuldades foram verificadas ao longo do processo, como a falta de tempo durante as aulas - sendo necessário realizar a maioria dos encontros no período oposto - e a escassez de materiais laboratoriais para a realização de experimentos mais complexos, por exemplo. Para que os resultados desse projeto sejam efetivos e para essa mudança de perfil motivacional realmente acontecer é necessária uma continuidade do projeto, mas não se limitando às aulas de Química, e sim com envolvimento de todo o corpo docente, coordenação e funcionários da escola.

Concluímos, então, que a realização de um projeto aonde os alunos possuíam autonomia e segurança para escolher, preparar e apresentar experimentos foi efetiva na satisfação das necessidades psicológicas básicas e contribuiu para o deslocamento, no continuum da motivação, do perfil motivacional dos alunos. Portanto, os resultados dessa investigação podem apontar caminhos para (re)organizar as atividades experimentais nas aulas de química, bem como para pensar e propor o estudo da motivação durante a formação continuada de professores.

Este trabalho buscou contribuir para um melhor aprofundamento sobre a motivação para o estudo da química, enfatizando a importância da realização de um processo de escolha, preparação e apresentação de experimentos na motivação dos alunos, relacionando à satisfação das necessidades psicológicas básicas durante esse processo com a promoção da motivação intrínseca. Conhecendo as teorias da motivação e as possibilidades de desenvolvê-las no ambiente escolar, os professores conseguem identificar de que maneira o aluno se sente motivado para uma determinada atividade, para assim tentar estimular a sua motivação intrínseca, tornando-o mais autodeterminado para a tarefa.

À semelhança desta pesquisa, outras podem investigar a relação entre a utilização de atividades experimentais e sua relação com a satisfação das necessidades psicológicas básicas em outras áreas do ensino de Ciências, como a Física e a Biologia, mostrando a importância da promoção da motivação em todos os aspectos da educação escolar.

De outra forma, as contribuições da relação entre um processo experimental e o deslocamento no continuum da motivação do perfil motivacional dos alunos podem auxiliar na compreensão de aspectos pouco explorados pelas pesquisas em educação em Ciências. Temos poucos trabalhos nessa área enfatizando a importância da satisfação das necessidades psicológicas básicas durante o desenvolvimento de atividades experimentais, a maioria destes trabalhos tratam apenas do levantamento do perfil motivacional dos alunos e dos fatores que influenciam na motivação. Diante disso, esse estudo abre caminhos para a continuidade e a realização de novas pesquisas que se aprofundem nas potencialidades de atividades que buscam a satisfação das necessidades psicológicas básicas e, consequentemente, a promoção da motivação dos alunos. De forma geral, a metodologia apresentada nesse estudo pode ser considerada para um processo de formação inicial e continuada de professores, para a análise de textos de pesquisa em educação em Ciências, para mediações de atividades experimentais em situação de ensino, entre outras possibilidades (Corrêa, 2009). 


\section{Referências}

Accorsi, D. M. P., Bzuneck, J. A., \& Guimarães, S. É. R. (2007). Envolvimento cognitivo de universitários em relação à motivação contextualizada. Psico-USF, 12(2), 291-300. http://dx.doi.org/10.1590/S1413-82712007000200017.

Appel-Silva, M., Wendt, G. W., \& Argimon, I.I.L.(2010). A teoria da autodeterminação eas influências socioculturais sobre a identidade. Psicologia em Revista, 2(16), 351-369. http:// pepsic.bvsalud.org/scielo.php?script=sci_arttext\&pid=S1677-11682010000200008

Bardin, L. (2009). Análise de Conteúdo. Edições 70.

Boruchovitch, E., \& Bzuneck, J. A. (2000). A motivação do aluno: Contribuições da psicologia contemporânea. Vozes.

Boruchovitch, E., Bzuneck, J. A., \& Guimarães, S. É. R. (2010). Motivação para aprender: Aplicações no contexto educativo. Vozes.

Brophy, J. (1983). Conceptualizing student motivation. Educational Psychologist, 18(3), 200-215. https://doi.org/10.1080/00461528309529274

Cardoso, S. P., \& Colinvaux, D. (2000). Explorando a motivação para estudar química. Química Nova, 23(3), 401-404. http://dx.doi.org/10.1590/S0100-40422000000300018.

Cavenaghi, A. R. A. (2009). Uma perspectiva autodeterminada da motivação para aprender língua estrangeira no contexto escolar. Ciências e Cognição, 14(2), 248-261. http://www.cienciasecognicao.org/revista/index.php/cec/article/view/101

Cernev, F. K, \& Hentschke, L. (2012). A teoria da autodeterminação e as influências das necessidades psicológicas básicas na motivação dos professores de música. Revista da ABEM, 20(29), 88-102.

Corrêa, R. G. (2009). Estudo do perfil motivacional para o aprendizado de química (6456) [Dissertação de Mestrado em Ciências Exatas e da Terra, Universidade Federal de São Carlos]. Repositório UFSCar.

Deci, E. L., \& Ryan, R. M. (1985). Intrinsic motivation and self-determination in human behavior. Plenum.

Giordan, M. (1999). O papel da experimentação no ensino de ciências. Química Nova na Escola, 10, 43-49. http://qnesc.sbq.org.br/online/qnesc10/pesquisa.pdf

Gonçalves, F. P. (2005). O texto de experimentação na educação em química: discursos pedagógicos e epistemológicos. (221333) [Dissertação de Mestrado em Educação Científica e Tecnológica, Universidade Federal de Santa Catarina]. https://repositorio. ufsc.br/handle/123456789/102437

Guimarães, C. C. (2009). Experimentação no Ensino de Química: caminhos e descaminhos rumo à aprendizagem significativa. Química Nova na Escola, 31(3), 198-202. http://webeduc.mec.gov.br/portaldoprofessor/quimica/sbq/QNEsc31_3/08RSA-4107.pdf 
Guimarães, S. É. R., \& Boruchovitch, E. (2004). O Estilo Motivacional do Professor e a Motivação Intrínseca dos Estudantes: uma perspectiva da teoria da autodeterminação. Psicologia: Reflexão e Crítica, 17(2), 143-150. https://doi.org/10.1590/S010279722004000200002

Hodson, D. (1994). Hacia un enfoque más crítico del trabajo de laboratorio. Enseñanza de Las Ciencias: revista de investigación y experiencias didácticas, 12(3), 299-313. https:// www.raco.cat/index.php/Ensenanza/article/view/21370

Kasseboehmer, A. C., Guzzi, M. E. R., \& Ferreira, L. H. (2012). Participação de estudantes em atividades investigativas: a influência do ambiente escolar para a motivação [Resumo]. Encontro Nacional de Ensino de Química, Salvador.

https://periodicos.ufba.br

Lüdke, M., \& André, M. E. D. A. (2012). Pesquisa em educação: Abordagens qualitativas. EPU.

Marangoni, A. M., Guzzi, M. E. R., Saldanha, R. M. P., \& Kasseboehmer, A. C. (2013). A motivação dos alunos para aprendizagem de química [Resumo]. Encontro Paulista de Pesquisa em Ensino de Química, Santo André. https://repositorio.usp.br/item/002421650

Neves, E. R. C., \& Boruchovitch, E. (2007). Escala de avaliação da motivação para aprender de alunos do ensino fundamental (EMA). Psicologia: Reflexão e Crítica, 20(3), 406-413. http://dx.doi.org/10.1590/S0102-79722007000300008

Oliveira, L. H. (2005). Exemplo de cálculo de Ranking Médio para Likert. Notas de Aula. Metodologia Científica e Técnicas de Pesquisa em Administração. Mestrado em Administração e Desenvolvimento Organizacional. PPGA CNEC/FACECA: Varginha.

Oliveira, J. R. S. (2010). A perspectiva sócio-histórica de Vygotsky e suas relações com a prática da experimentação no ensino de química. Revista de Educação em Ciência e Tecnologia, 3(3), 25-45. https://periodicos.ufsc.br/index.php/alexandria/article/ view/38134

Pintrich, P. R., \& Schunk, D. H. (2002). Motivation in Education: Theory, Research, and Applications. Merrill.

Pontes, A. N, Serrão, C. R. G., Freitas, C. K. A., Santos, D. C. P., \& Batalha, S. S. A. (2008). O ensino de química no nível médio: um olhar a respeito da motivação [Resumo]. Encontro Nacional de Ensino de Química, Curitiba. http://www.quimica.ufpr.br/ eduquim/eneq2008/resumos/R0428-1.pdf

Pozo, J. I., \& Crespo, M. A. G. (2009). A Aprendizagem e o Ensino de Ciências: Do conhecimento cotidiano ao conhecimento científico. Artmed.

Ryan, R. M., \& Deci, E. L. (2000). Self-Determination Theory and the Facilitation of Intrinsic Motivation, Social Development, and Well-Being. American Psychologist, 55(1), 68-78. https://doi.org/10.1037110003-066X.55.1.68 
Ryan, R. (2009). Self-determination Theory and Wellbeing. Wed Research Review, 1, 1-2. http://www.bath.ac.uk/soc-pol/welldev/wed-new/network/research-review/Review_1_ Ryan.pdf

Severo, I. R. M. (2014). Levantamento do perfil motivacional de alunos, do ensino médio, de três escolas públicas da cidade de São Carlos/SP, na disciplina de Química. (10.11606/D.75.2015.tde-16042015-111507) [Dissertação de Mestrado em Química Orgânica e Biológica, Universidade de São Paulo]. Biblioteca Digital de Teses e Dissertações da USP.

Soares, M. B., \& Fazenda, I. (1992). Metodologias não-convencionais em teses acadêmicas. In I. Fazenda (Org.), Novos enfoques da pesquisa educacional (23-26). Cortez.

Thomaz, M. F. (2000). A experimentação e a formação de professores de ciências: uma reflexão. Caderno Brasileiro de Ensino de Física, 17(3), 360-369. https://doi. org/10.5007/\%25x

Van den Broeck, A. (2010). Capturing autonomy, competence, and relatedness at work: construction and initial validation of the work-related basic need satisfaction scale. Journal of Occupational and Organizational Psychology, (83), 981-1002. https://selfdeterminationtheory.org/SDT/documents/2010_ VandenBroeckVansteenkisteNSscale_JOOP.pdf

Vernon, M. D. (1973). Motivação Humana: A força interna que emerge, regula e sustenta todas as nossas ações. Vozes.

Vygotsky, L. S. (1991). A formação social da mente. Martins Fontes.

\section{Anexos}

\section{Questionário Aberto 1 (QA1):}

1. Por que você decidiu participar do projeto?

2. Por que você estuda química?

3. Quais são suas maiores dificuldades nas aulas de química?

4. Quando o professor propõe uma atividade você prefere trabalhar em grupo ou sozinho? Por quê?

5. Quando você vai realizar um trabalho em grupo prefere liderar esse grupo distribuindo as funções de cada membro ou prefere esperar que alguém faça esse serviço? Por quê?

6. Quando você tem um bom desempenho nas aulas ou nas avaliações de química, a que você atribui esse resultado?

7. Você gosta de estudar junto com seus amigos ou prefere estudar sozinho? Por quê? 
8. Durante as aulas no laboratório: você prefere que o professor realize o experimento primeiro para que depois você realize também ou prefere tentar fazer sozinho sem as instruções prévias do professor? Por quê?

9. Quando você está na sala de aula, em uma aula de química, quais são os fatores que levam você a não participar e não prestar a atenção na aula?

10. Você se sente capaz de apresentar experimentos, que você mesmo tenha escolhido, preparado e estudado antecipadamente, para um grupo de pessoas? Por quê?

11. No caso da escolha dos experimentos: você prefere escolhê-los sozinho; prefere que o professor escolha para você apresentar; prefere escolher, mas com ajuda do professor. Por quê?

12. Você costuma sair bastante com os seus amigos? O que vocês costumam fazer quando estão juntos?

13. Você acha que tem conhecimento o suficiente para apresentar os experimentos, que você tenha escolhido, preparado e estudado antecipadamente, para o público? Por quê?

14. No laboratório: você prefere que o professor dê um roteiro com os passos para a realização do experimento ou que deixe você livre para encontrar a melhor maneira de realizar o experimento? Por quê?

15. Quais são seus principais objetivos em uma aula de química?

16. Você se sente capaz de explicar aos seus amigos os conteúdos vistos nas aulas de química? Por quê?

17. Você tem um bom relacionamento com os seus colegas de sala? Você os considera amigos ou apenas colegas?

18. Você costumar resolver seus problemas pessoais e tomar decisões importantes sozinho ou sempre precisa da ajuda de alguém? Por quê?

19. Você faz ou já fez algum curso fora da escola? Qual (is)?

20. O que você gosta de fazer nos fins de semana?

\section{Questionário Aberto 2 (QA2):}

1. Por que você decidiu participar do projeto?

2. Qual o principal motivo de estudar química?

3. Em quais momentos das aulas de química você sente mais dificuldade?

4. Durante a atividade você gostou de trabalhar em grupo ou preferia ter trabalhado sozinho? Por quê?

5. Durante a realização dos trabalhos você optou por coordenar e distribuir as funções de cada membro ou esperou que alguém fizesse esse serviço? Por quê? 
6. Ao longo do ano, quando você obteve bom desempenho nas aulas ou nas avaliações de química, a quais motivos você atribuiu esses resultados?

7. Você tem o hábito de estudar com seus amigos ou prefere estudar sozinho? Por quê?

8. Durante a realização das atividades no laboratório: você achou bom realizar os experimentos somente com seu grupo ou gostaria que o professor tivesse dado todas as instruções? Por quê?

9. Durante as aulas de química, em sala de aula, quais são os motivos que levam você a não prestar atenção no professor e no conteúdo?

10. Após a escolha, preparação e estudo antecipado, você se sentiu capaz para apresentar os experimentos para o público? Por quê?

11. No caso da escolha dos experimentos: você achou bom escolhê-los somente com o grupo, gostaria que o professor tivesse escolhido para vocês ou gostaria de escolher com a ajuda do professor? Por quê?

12. Você costuma sair bastante com os seus amigos? O que vocês costumam fazer quando estão juntos?

13. Após escolher, preparar e estudar antecipadamente, você achou que tinha conhecimento suficiente para apresentar os experimentos para o público? Por quê?

14. Nas aulas do laboratório: você gosta mais quando o professor fornece um roteiro para a realização do experimento ou quando você fica livre para encontrar a melhor forma de realizar o experimento? Por quê?

15. Quais são seus objetivos em uma aula de química? Eles estão sendo atingidos? Por quê?

16. Você se sente capaz de explicar e ajudar seus amigos com os conteúdos vistos nas aulas de química? Por quê?

17. Você tem um bom relacionamento com os seus colegas de sala? Você os considera amigos ou apenas colegas?

18. Quando você precisa resolver um problema ou tomar uma decisão, o que você faz: resolve sozinho ou pede ajuda de alguém? Por quê?

19. Você faz ou pretende fazer algum curso fora da escola? Qual(is)?

20. O que você costuma fazer nos finais de semana?

\section{Questionário Likert 1 (QL1):}

1. Não sei por que vou à aula de química e sinceramente não ligo para isso.

2. Faço as atividades de química porque a professora dá visto ou porque vale nota.

3. Estudo química porque me sinto culpado(a) se não entrego uma atividade. 
4. Estudo química porque o diploma de ensino médio pode me ajudar a conseguir um emprego que pague um salário bom.

5. Estudo química para melhorar meu conhecimento.

6. Estudo química pelos momentos de satisfação que experimento quando falo das minhas ideias para a turma.

7. Gostaria que não existissem aulas de química.

8. Estudo química porque meus pais ou responsáveis me mandam vir à escola.

10. Estudo química pois ajudará na minha profissão.

11. Estudo química para aprender coisas novas e/ou desafiadoras.

12. Estudo química pela satisfação que sinto ao descobrir coisas que nunca tinha visto antes.

13. Não tenho interesse em entender o que é química.

14. Só estudo química para não reprovar.

15. Preciso fazer as tarefas de química para poder entender o conteúdo, senão não consigo ir bem na prova.

16. Estudo química para passar no vestibular.

17. Gosto das aulas de química, porque o assunto discutido me deixa curioso.

18. Estudo química pela satisfação que sinto quando estou completamente envolvido com o conteúdo apresentado na sala de aula.

19. Honestamente, não sei, acho que estou perdendo meu tempo nas aulas de química.

20. Porque quero levar uma boa vida no futuro.

21. Por causa do fato que me sinto importante quando sou bem sucedido(a) na escola.

22. Porque me ajudará a escolher melhor minha carreira profissional.

23. Porque a educação é um privilégio.

24. Porque para mim estudar é um prazer.

25. Não vejo que diferença faz assistir as aulas de química.

26. Porque gosto de ficar com meus amigos durante as aulas.

27. Estudo química porque é isso que esperam de mim.

28. Porque a frequência e participação nas aulas são necessárias para a aprendizagem.

29. Porque estudar amplia os horizontes.

30. Pelo prazer que tenho em ampliar meu conhecimento sobre assuntos que me atraem. 


\section{Questionário Likert 2 (QL2):}

1. O prazer que tenho em ampliar meu conhecimento sobre assuntos que me atraem.

2. Estudar amplia os horizontes.

3. A frequência e participação nas aulas são necessárias para a aprendizagem.

4. É isso que esperam de mim.

5. Ficar com meus amigos durante as aulas.

6. Não vejo que diferença faz assistir as aulas de química.

7. Estudar é um prazer.

8. Educação é um privilégio.

9. Me ajudará a escolher melhor minha carreira profissional.

10. Sinto-me importante quando sou bem sucedido(a) na escola.

11. Quero levar uma boa vida no futuro.

12. Honestamente, não sei, acho que estou perdendo meu tempo nas aulas de química.

13. A satisfação que sinto quando estou completamente envolvido com o conteúdo apresentado na sala de aula.

14. Gosto das aulas de química, porque o assunto discutido me deixa curioso.

15. Passar no vestibular.

16. Preciso fazer as tarefas de química para poder entender o conteúdo, senão não consigo ir bem na prova.

17. Não reprovar.

18. Não tenho interesse em entender o que é química.

19. A satisfação que sinto ao descobrir coisas que nunca tinha visto antes.

20. Aprender coisas novas e/ou desafiadoras.

21. Ajudará na minha profissão.

22. Testar a minha inteligência

23. Meus pais ou responsáveis me mandam vir à escola.

24. Gostaria que não existissem aulas de química.

25. Os momentos de satisfação que experimento quando falo das minhas ideias para a turma.

26. Melhorar meu conhecimento.

27. O diploma de ensino médio pode me ajudar a conseguir um emprego que pague um salário bom. 
28. Sinto-me culpado(a) se não entrego uma atividade.

29. Faço as atividades de química porque a professora dá visto ou porque vale nota.

30. Não sei por que vou à aula de química e sinceramente não ligo para isso.

\author{
Beatriz Derisso Faitanini \\ Universidade Federal de São Carlos \\ São Carlos, São Paulo, Brasil \\ biaderisso@hotmail.com \\ ${ }^{-}$Paulo Sergio Bretones \\ Universidade Federal de São Carlos \\ São Carlos, São Paulo, Brasil \\ bretones@ufscar.br
}

Editor Responsável

Stefannie Ibraim

Manifestação de Atenção às Boas Práticas Científicas e de Isenção de Interesse

Os autores declaram ter cuidado de aspectos éticos ao longo do desenvolvimento da pesquisa e não ter qualquer interesse concorrente ou relações pessoais que possam ter influenciado o trabalho relatado no texto. 